\title{
USAHATANI PADI SAWAH (Oryza sativa, L.) DENGAN PENERAPAN PENGENDALIAN HAMA TERPADU (PHT)
}

\author{
Pandu Sumarna*
}

\section{ABSTRAK}

Padi sawah (Oryza sativa, L) merupakan salah satu tumbuhan yang menghasilkan sumber pangali pokok bagi masyarakat Indonesia. Keberhasilan usaha peringkatan produksi padi sawah sangat tergantung pata daya dukung dan kemampuan pelani sebagai pengelola usaha tani, antara lain penyediaan modal, tingkat pengetahuan dan keterampilan yang dimiliki petani serta luas kepemilikan lahan garapan yang dikelola petani.

Ḱendala dalam peningkatan produksi tancman padi antara lain serangan hama dan penyakit tanaman yarg menyerang tanaman sejak di persenaian sampai menjelang panen. Serangan hama dan penyakit ini dapat mengurangi hasil produksi baik kualitas maupun kuantitas bahkan sampai mengakibatkan kegagalan panen. Oleh karena itu upaya pengendalian serangan hama dan penyakit perlu mendapat perhatian yang serius agar produksi dapat dipertahankan dan petan; memperoleh keuntungan dalam mengelola usahanya.

Berdasarkan hasil penelitian dapat disimpulkan bahwa usatani dengan penerapan PHT mengeluarkan biaya total sebesar Rp 5.276.930,60 per hektar dan menghasilkan penerimaan sebesar Rp 8.050.900,53 per hektar, sehingga diperoleh keuntungan sebesar Rp 2.773.969,93 per hektar. Adapun tingkat efisiensi usahatani yang menerapkan PHT, tingkat effisiensinya ( $R C$ ) sebesar 1,53. Begitu pula bila dilihat dari kelayakan usahanya (renatabilitas) memperoleh 52,57 lebih tinggi dari bunga Bank sebesar 6 persen per musim. Hal ini menunjukkan usahatani yang menerapkan PHT dalam usahataninya layak untuk dikembangkan.

Kata kunci: pengendalian, padi, petani, hama terpadu, usahatani 


\section{PENDAHULUAN}

Podi sawain ( Oijza sativa, L. ) merupakan salah satu tumbuhan yang menghasilkan sumber pangan pokok bagi masyarakat Indonesia. Upaya peningkatan produktivitas usahatanj tersebut terus dilakukan dari tahun ke talun guna momenuhi kebutuhan pangan penduduk yang terus meningkat.

Keberhasilan t:Saha peningkatan produksi padi sawah saligat tergantung pada daya cukurg dan kemampuan petani sebagai pengelola usahatani, antara lain penyediaan modal, tingkat pengetahuan dan keterampilan yang dimiliki petani serta luas kepemilikan lahan garapan yang dikelola petani.

Fcrimbuhan penducuk yang relatif tinggi dan gerak pembangunan industri yang terus berkenbang; megakibatkan lahan pertanian semakin berkurang, sehingga produksi pertanian khususnya padi semakin bcrkuraing. Keadaan ini meigancan liclesiaiian swasembada pangan ( padi), apalagi Jawa Barat schanai limbung bcris nasional:

Selain iu, kendala lain dalam peningkatan produksi tanaman padi antara lain scrangan hama dan penyakit tanaman yang menyerang tanaman sejak di persemaian sampai menjelang panen. Serangan hama dan penyakit ini dapat mengurangi hasil produksi baik kualitas maupun kuantitas bahkan sampai mengakibatkan kegagalan panen. Berdasarkan data cari rata - rata 10 tahun terakhir baiwa luas areal tanaman yang terserang mencapai 14,785 ha untuk wereng collat dan 11,792 ha untuk tikus (Rattus argentiventer) ( Dinas Pcrtanian dan Peternakan Kabupaten Indramayu, 2010 ). Oleh karena itu upaya pengendalian serangan hama dan penyakit perlu mendapat peihatian yang serius agar produksi dapat dipcrtahankan dan petani memperoleh keuntungan dalam mengelola usahanya.

Upaya pengendalian hama dan penyakit tanaman pada awalnya dititikberatkan pada penggunaan pestisida. Hal ini karena pestisida dapat dengan cepat menurunkan populasi hama dan dapat digunakan kapan saja, di mana saja serta menunjukkan hasil yang cukup baik. Namun pada hakekatnya masalah hama semakin kompleks dan sukar dikendalikan. Menurut Ida Nyoman Oka ( 1995 ) berbagai jenis pestisida memberikan pengaruh yang negatif terhadap lingkungan dan hama yang lainnya, seperti hama menjadi resisten, timbulnya resurgensi, terbunuhnya musuh alami dan menimbulkan pencemaran udara. Keadan ini akan mengakibatkan biaya pengendalian hama semakin besar, sehingga biaya produksi semakin besar pula yang pada akhirnya petani akan menderita kerugian. 
Walaupun penerapan PHT telah menurunkan luas serangan hama dan meningkatkan produksi, namun dalam mengelola usahatani padi sawah para petani ini masih beragam ada yang telah menerapkan Pengendalian Hama Terpadu ( PHT ), namun banyak pula petani yang tidak menerapkan PHT tersebut.

Keadan demikian membuat Penulis tertarik untuk mengadakan penelitian tentang “ Analisis Usahatani Padi Sawah (Oryza sativa, L. ) dengan Penerapan Pengendalian Hama Terpadu ", di Kelompok Tani Samurai Desa Majasih Kecamatan Sliyeg Kabupaten Indramayu Musim Tanam 2010/2011.

\section{Permasalahan}

Berdasarkan latar belakang tersebut di atas, maka permasalahan yang timbul dilapangan adalah :

1. Berapa besar biaya usahatani padi sawah dengan menerapkan PHT.

2. Berapa besar penerimaan dan keuntungan usahatani padi sawah dengan menerapkan PHT.

3. Berapa besar Revenue Cost Ratio ( RC Rasio ) dari usahatani padi sawah dengan menerapkan PHT.

4. Berapa besar Rentabilitas dari usahatani padi sawah dengan menerapkan PHT.

\section{Pendekatan Masalah}

Salah satu upaya dalam rangka mempertahankan swasembada pangan khususnya beras, pemerintah melaksanakan kegiatan intensifikasi, ekstensifikasi dan diversifikasi. Dismping itu dalam mendukung keberhasilan intensifikasi pemerintah pun menaruh perhatian terhadap Pengendalian Hama Terpadu ( PHT ) pada tanaman padi.

Konsep Pengendalian Hama Terpadu ( PHT ) merupakan alternatif jawaban yang tepat untuk menghadapi hama tanaman, sebab PHT merupakan suatu teknologi pengendalian hama yang sangat bersahabat dengan ling!: Ingan dan meningkatkan efisiensi biaya.

Konsep PHT merupakan cara pendekatan pengendalian hama yang didasarkan pada pertimbangan ekologi dan ekonomi (Kasumbogo Untung, 2002). Pengendalian hama secara bercocok tanam ( kultur teknis) 
sering pula disebut sebagai pengendalian agroekonomis. Pengendalian ini bertujuan untuk mengelola lingkungan tanaman agar lingkungan tersebut tidak sesuai untuk perkembangan populasi hama, sehingga dapat mengurangi populasi hama dan tingkat kerusakannya pada tanaman. Usaha ini bersifat preventif dan dilaksanakan sebelum hama menyerang tanaman. Kegiatan-kegiatan pengendalian secara bercocok tanam antara lain adalah ; penggunaan benih unggul, pengolahan tanah, tanam serempak, pergiliran varietas, pengelolaan air, pemupukan berimbang, pola tanam, dan sanitasi.

\section{METODE PENELITIAN}

Penelitian ini dilakukan dengan menggunakan metode survey terhadap Kelompok Tani Samurai di Desa Majasih Kecamatan Sliyeg Kabupaten Indramayu.

\section{Analisis Data}

Analisis data yang digunakan dalam penelitian ini adalah :

1. Untuk mengukur keuntungan digunakan rumus sebagai berikut :

$\pi=\mathrm{TR}-(\mathrm{FC}+\mathrm{VC})$

Keterangan :

$\pi \quad$ : Keuntungan (Rp)

TR : Total Revenue / Penerimaan Total (Rp)

FC : Fixed Cost / Biya Tetap (Rp)

$\mathrm{VC}$ : Variable Cost / Biaya Variabel (Rp)

Untuk mengetahui TR digunakan rumus sebagai berikut :

$\mathrm{TR}=\mathrm{Y}$. Hy

Keterangan :

TR : Total Revenue / Penerimaan Total ( $\mathrm{Rp})$

Y : Hasil Produksi (kg)

Hy : Harga satuan hasil produksi $(\mathrm{Rp} / \mathrm{kg})$

2. Untuk mengetahui efisiensi usahatani digunakan rumus :

$$
\mathrm{R} / \mathrm{C}=\frac{\mathrm{R}}{(\mathrm{FC}+\mathrm{VC})}
$$

Ke:arangan :

$\mathrm{R}$ : Revenue/ Penerimaan ( $\mathrm{Rp}$ )

FC : Fixed Cost / Biaya Tetap (Rp)

VC : Variable Cost / Biaya Variabel (Rp) 
R/C kurang dari 1, usahatani tersebut tidak efisien.

$R / C$ sama dengan 1 , usahatani tersebut impas.

$\mathrm{R} / \mathrm{C}$ lebih dari 1, usahatani tersebut efisien.

3. Untuk mengetahui rentabilitas usahatani digunakan rumus sebagai berikut :

Rentabilitas $=\frac{\pi}{(\mathrm{FC}+\mathrm{VC})} \times 100 \%$.

Keterangan :

$\mathrm{R}$ : Rentbilitas

$\pi \quad$ : Keuntungan $(\mathrm{Rp})$

FC : Fixed Cost / Biaya Tetap (Rp)

VC : Variable Cost / Biaya Variabel (Rp)

\section{HASIL PENELITIAN DAN PEMBAHASAN}

1) Analisis Biaya Produksi dan Penerimaan Biaya Usahatani

Komponen biaya yang di analisis adalah biaya tetap, biaya variabel dan biaya total.

A. Biaya tetap

Menurut Soeharjo dan Dahlan Patong (2003) menyatakan bahwa biaya tetap adalah biaya yang jumlahnya tidak dipengaruhi oleh hasil produksi. Biaya tetap ini meliputi sewa lahan, pajak, iuran pengairan, penyusutan alat, dan bunga modal.

Rata -rata biaya tetap adalah biaya yang dikeluarkan seperti sewa lahan, pajak, iuran pengairan, penyusutan alat dan bunga modal. Biaya tetap petani yang menerapkan PHT yakni Rp 2.761.664,11 / hektar seperti dalam Tabel 1 berikut ini.

Tabel 1.

Rata - rata Biaya Tetap Petani yang menerapkan PHT di Desa Majasih

\begin{tabular}{|c|l|c|}
\hline No. & \multicolumn{1}{|c|}{ Komponen Biaya Tetap } & Nilai ( Rp/ha ) \\
\hline 1. & Sewa Lahan & $2.113 .688,65$ \\
\hline 2. & PBB & $35.149,54$ \\
\hline 3. & Iuran Pengairan & $70.053,68$ \\
\hline 4. & Iuran Desa & $224.171,78$ \\
\hline 5. & Penyusutan Alat & $23.504,60$ \\
\hline 6. & Bung Modal & $295.095,86$ \\
\hline \multicolumn{2}{|c|}{ Jumlah } & $2.761 .664,11$ \\
\hline
\end{tabular}




\section{a. Biaya Variabel}

Biaya variabel adalah biaya yang jumlah besar kecilnya mempengruhi hasil yang ingin dicapai. Biaya variabel ini meliputi benih, pupuk, pestisida, dan tenaga kerja. (Soeharjo dan Dahlan Patong, 2003 ). Rata - rata biaya variabel petani yang menerapkan PHT disajikan dalam Tabei 2.

Tabel 2.

Ratâ-rata Biaya Variabel Petani yang menerpkan PHT di Desa Majasih (Rp).

\begin{tabular}{|c|l|c|}
\hline No. & \multicolumn{1}{|c|}{ Uraian } & Nilai (Rp/ha ) \\
\hline 1. & Bibit & $57.745,40$ \\
\hline 2. & Pupuk & $686.915,26$ \\
\hline 3. & Pestisida & $90.605,83$ \\
\hline 4. & Tenga Kerja & $1.680 .000,00$ \\
\hline \multicolumn{2}{|c|}{ Jumlah } & $2.515 .266,49$ \\
\hline
\end{tabular}

Benih yang digunakan petani yang mencrapkn PHT adalak benih varictas Cikerang dengan rata -rata biayanya sebesar $R p 57.745,40$. Pupuk yang digunakan oleh petani PHT adalah Urea, SP - $36100 \mathrm{Kg} / \mathrm{ha}$, dan Phonska $150 \mathrm{Kg} / \mathrm{ha}$. Biaya untuk pembelian pupuk sebesar Rp 686.915,26 / ha.

Pestisida yang banyak digunakan adalah Furadan dan Spontan. Penggunaan pestisida oleh petani PHT relatif kecil yakni sebesar Rp $90.605,83$. Penggunaan pestisida yang relatif kecil akan meningkatkan efisiensi biaya. Tenaga kerja yang digunakan dalam usahatani pada umumnya adalah tenaga kerja dewasa dan tenaga kerja wanita. Curahan tenaga kerja ini dimulai dari kegiatan persemaian hingga kegiatan panen. Rata - rata biaya tenaga kerja petani yang menerapkan PHT disajikan dalam Tabel 3

Tabel 3 di bawah ini menunjukan bahwa curahan tenaga kerja petani yang menerapkan PHT sebanyak $88 \mathrm{HKSP}$. Hal ini karena PHT memerlukan pengamatan yang berulang - ulang dan padat tenaga kerja. Biaya untuk tenaga kerja petani PHT sebesar Rp 1.680.000,00.

\section{B. Biaya Total}

Biaya total merupakan penjumlahan dari biaya tetap dan biaya variabel. Biaya total ini salah satu komponen dalam menentukan keuntungan usahatani, selain dari penerimaan. Rata - rata biaya total usahatani padi sawah petani yang menerapkan PHT disajikan dalam Tabel 4 berikut ini. 
Tabel 3.

Rata-rata Biaya Tenaga Kerja Petani yang menerapkan PHT di Desa Majasih.

\begin{tabular}{|c|l|c|r|r|}
\hline \multirow{2}{*}{ No. } & \multicolumn{1}{|c|}{ Uraian } & \multicolumn{3}{|c|}{ Petani PHT } \\
\cline { 3 - 5 } & & $\begin{array}{c}\text { Curahan Tenaga } \\
\text { Kerja (HKSP) }\end{array}$ & $\begin{array}{c}\text { Upah Tenag Kerja } \\
\text { (Rp/HKSP) }\end{array}$ & $\begin{array}{c}\text { Jumlah } \\
\text { Upah (Rp) }\end{array}$ \\
\hline 1 & Persemaian & 3 & $25.000,00$ & $75.000,00$ \\
\hline \multirow{3}{*}{2} & Pengolahan Tanah & & & \\
\cline { 2 - 5 } & a. Traktor & - & & $280.000,00$ \\
\cline { 2 - 5 } & b. Manusia & 5 & $25.000,00$ & $125.000,00$ \\
\hline 3 & Tanam & 29 & $15.000,00$ & $435.000,00$ \\
\hline \multirow{4}{*}{4} & Pemeliharaan : & & & \\
\cline { 2 - 5 } & a. Pemupukan & 13 & $15.000,00$ & $195.000,00$ \\
\cline { 2 - 5 } & b. Penyiangan & 17 & 15.000 & $255.000,00$ \\
\cline { 2 - 5 } & c. Pergamatan & 16 & 15.000 & $240.000,00$ \\
\cline { 2 - 5 } & d. Penyemperotan & 5 & & $75.000,00$ \\
\hline \multicolumn{2}{|c|}{ Jumlah } & 88 & & $1.680 .000,00$ \\
\hline
\end{tabular}

Tabel 4.

Rata - rata Eizya Usahatani yang menerapkan PHT di Desa Majasih.

\begin{tabular}{|c|l|c|}
\hline No. & \multicolumn{1}{|c|}{ Uraian } & Nilai ( $\mathrm{Rp} / \mathrm{ha})$ \\
\hline 1 & Biaya Tetap & $2.761 .664,11$ \\
\hline 2 & Biaya Variabel & $2.515 .266,49$ \\
\hline \multicolumn{2}{|c|}{ Jumlah } & $5.276 .930,60$ \\
\hline
\end{tabular}

\section{2) Penerimaan dan Keuntungan}

Rata - rata produksi yang dihasilkan petani yang menerapkan PHT sebesar 6.286,77 kg. Hal ini karena petani yang menerapkan PHT menggabungkan berbagai cara pengendalian hama.

Harga jual yang diterima petani pelaksana PHT sangat berbeda - beda dengan rata - rata sebesar $\mathrm{Rp} 1.280,61$, sehingga rata - rata penerimaan petani yang menerapkan PHT sebesar Rp 8.050.900,53/ha, sedangkan biaya usahatani sebesar Rp 5.276.930,60. Keuntungan usahatani yang diperolehnya sebesar Rp 2.773.969,93/ha. Besarnya penerimaan dan keuntungan yang diperoleh petani yang menerapkan PHT disajikan pada Tabel 5.

Tabel 5.

Rata - rata Produksi, Harga, Penerimaan dan Keuntungan Petani yang menerapkan PHT di Desa Majasih.

\begin{tabular}{|c|l|r|}
\hline No. & \multicolumn{1}{|c|}{ Uraian } & \multicolumn{1}{|c|}{ Nilai } \\
\hline 1 & Produksi & $6.286,77$ \\
\hline 2 & Harga ( Rp/kg) & $1.280,61$ \\
\hline 3 & Penerimaan (Rp) & $8.050 .900,53$ \\
\hline 4 & Biaya Usahatani (Rp) & $5.276 .930,60$ \\
\hline 5 & Keuntungan (Rp) & $2.773 .969,93$ \\
\hline
\end{tabular}




\section{3) Analisis RC}

Suatu kegiatan usahatani dapat dikatakan modern bila usahatani tersebut (a) Efisien dan teknologi yang selalu diperbaiki, (b ) Hasil produksi terus berubalı sejalan dengan perubahan permintaan konsumen dan pcrubahan biaya produksi, ( c ) Perbandingan penggunaan lahan, tenaga kerja, dan modal paủa usahatani terus berubah sesuai dengan perubahan penduduk, alternatif kesempatan kerja, dan teknologi usabatani ( Mosher, 1990 ).

Untuk menentuikan keberhasilan usahatani dapat diukur dengan RC Rasio. Bila RC Rasio kurang dari satu, maka usahatani tersebut tidak menguntungkan. Bila RC Rasio sama dengan satu maka usahatani tersebut tidak menguntungkan dan tidak merugikan. Usahatani akan menguntungkan bila RC Rasio lebih besar dari satu. RC Rasio petani yang menerapkan PHT sebesar 1,53 seperti terlihat dalam Tabel 6.

Tabel 6.

Rata - rata RC Rasio Petani PHT Padi Sawah di Desa Majasih

\begin{tabular}{|c|l|r|}
\hline No. & \multicolumn{1}{|c|}{ Uraian } & \multicolumn{1}{|c|}{ Nilai } \\
\hline 1. & Penerimaan per $\mathrm{Ha}(\mathrm{Kp})$ & $8.050 .900,53$ \\
\hline 2. & Biaya Usahatani per $\mathrm{Ha}(\mathrm{Rp})$ & $5.276 .930,60$ \\
\hline 3. & RC Rasio & 1,53 \\
\hline
\end{tabular}

Tabel 6 diatas memperlihatkan bahwa RC Rasio petani PHT usahatani padi sawah sebesar 1,53. Hal ini berarti bahwa setiap seratus rupiah biaya produksi yang dikeluarkan akan memperoleh penerimaan sebesar seratus lima puluh tiga rupiah

\section{4) Analisis Rentabilitas}

Rentabilitas digunakan untuk mengukur kelayakan suatu usahatani. Usahatani akan menguntungkan ( profitable) bila rentabilitasnya lebih besar dari suku bunga bank untuk kegiatan pertanian. Usahatani tersebut dikatakan tidak menguntungkan ( unprofitable ) bila rentabilitasnya lebih kecil dari suku bunga bank pemerintah. Rentabilits responden petani PHT di Desa Majasih disajikan dalam Tabel 7.

Tabel 7.

Rentabilitas Usahatani Padi Sawah Petani PHT di Desa Majasih

\begin{tabular}{|c|l|r|}
\hline No. & \multicolumn{1}{|c|}{ Uraian } & \multicolumn{1}{|c|}{ Nilai } \\
\hline 1. & Biaya Usahatani per $\mathrm{Ha}(\mathrm{Rp})$ & $5.276 .930,60$ \\
\hline 2. & Keuntungan per $\mathrm{Ha}(\mathrm{Rp})$ & $2.773 .969,93$ \\
\hline 3. & Rentabilitas (\%) & 52,57 \\
\hline
\end{tabular}


Tabel 7 menunjukan bahwa rentabilatas petani PHT usahatani padi sawah sebesar 52,57 \%. Ini berarti penerapan PHT pada usahatani padi sawah sangat layak. Hal ini karena rentabilitas usahatani padi sawah dengan menerapkan PHT 52,57 \% lebih besar dari suku bunga pinjaman Bank BRI untuk pertanian yakni sebesar $18 \%$ per tahun atau $6 \%$ per musim.

\section{KESIMPULAN}

Berdasarkan hasil pembahasan dapat disimpulkan sebagai berikut :

1. Biaya usahatani padi sawah yang menerapkan PHT sebesar Rp $5.276 .930,60$.

2. Penerimaan usahatani padi sawah yang menerapkan PHT sebesar Rp $8.505 .900,53$. Keuntungan yang diterima petani yang menerapkan PHT sebesar Rp 2.773.969,93.

3. RC Rasio dari usahatani padi sawah yang menerapkan PHT 1,53. Ini berarti setiap seratus rupiah biaya produksi yang dikeluarkan akan memperoleh penerimaan sebesar seratus lima puluh tiga rupiah.

4. Rentabilitas $52,57 \%$ per musim lebih besar dari bunga pinjaman bank pemerintah yakni sebesar $6 \%$ per musim, sehingga usahatani dengan penerapan PHT ini layak untuk dilaksanakan.

\section{DAFTAR PUSTAKA}

Dinas Pertanian dan Peternakan Kabupaten Indramayu, 2010. Laporan Tahunan 2010.

Fadholi Hernanto, 1988. Ilmu Usahatani. Penebar Swadaya, Jakarta.

Ida Nyoman Oka, 1995. Pengendalian Hama Terpadu dan Implementasinya di Indonesia. Gajah Mada University Press, Yogyakarta.

Kasumbogo Untung,2002. Pengantar Pengelolaan Hama Terpadu. Gajah Mda University Press, Yogyakarta.

Mosher, 1990. Menggerakkan dan Membangun Pertanian. CV. Yasaguna, Jakarta. Moh. Nazir, 1988. Metodologi Penelitian. PT. Ghalia Indonesia, Jakarta.\#\#

*) Pandu Sumarna adalah Staf Pengajar Fakultas PertanianUniversitas Wiralodra 